\title{
Increased mitochondrial common deletion in platelets from patients with type 2 diabetes is not associated with abnormal platelet activity or mitochondrial function
}

\author{
AYLA KARIMOVA ${ }^{1}$, YALÇIN HACIOĞLU ${ }^{2}$, NURTEN BAHTIYAR ${ }^{3}$, MUTLU NIYAZOĞLU $^{4}$, \\ FAHRI AKBAŞ $^{5}$, ERKAN YILMAZ ${ }^{6}$, TURGUT ULUTIN ${ }^{1}$ and ILHAN ONARAN $^{1}$ \\ ${ }^{1}$ Department of Medical Biology and Genetics, Cerrahpasa Faculty of Medicine, Istanbul University; \\ ${ }^{2}$ Department of Family Medicine, Istanbul Training and Research Hospital; ${ }^{3}$ Department of Biophysics, \\ Cerrahpasa Faculty of Medicine, Istanbul University; ${ }^{4}$ Department of Endocrinology, Istanbul Training and Research Hospital, \\ 34098 Istanbul; ${ }^{5}$ Department of Medical Biology, Faculty of Medicine at Bezmialem Vakif University, 34093 Istanbul; \\ ${ }^{6}$ Tissue Typing Laboratory, Cerrahpasa Faculty of Medicine, Istanbul University, 34098 Istanbul, Turkey
}

Received February 12, 2018; Accepted July 7, 2018

DOI: $10.3892 / \mathrm{mmr} .2018 .9340$

\begin{abstract}
The present study examined the presence and frequency of the 4,977-base pair mitochondrial (mt)DNA $\left(\mathrm{mtDNA}^{4977}\right)$ deletion in blood platelets, and whether increased mtDNA $^{4977}$ deletion was associated with abnormal mitochondrial and platelet function in type 2 diabetes mellitus. A total of 66 patients with type 2 diabetes mellitus and 23 healthy subjects were included in the present study. Patients were divided into three subgroups according to glycemic control, and the presence or absence of chronic diabetic complications: i) Good glycemic control [glycated hemoglobin (HbAlc) <7] without complications; ii) poor glycemic control (HbAlc $\geq 7)$ without complications; and iii) poor glycemic control (HbAlc $\geq 7)$ with complications. mtDNA ${ }^{4977}$ deletion, mtDNA copy number, adenine nucleotides, mitochondrial membrane potential and P-selectin expression levels were analyzed in platelets. Although the frequency of mtDNA $^{4977}$ deletion in platelets of the patient $(96.9 \%)$ and control groups $(95.6 \%)$ was extremely similar, the deletion level significantly increased in all the diabetic groups, compared with the healthy control group. However, the data from the present study revealed that an increased deletion frequency in platelets was not associated with disease severity, although there was clear interindividual variability. Furthermore, all other parameters were not significantly different among the groups, and there were no correlations between mtDNA ${ }^{4977}$ deletion frequency and all other studied parameters for any of the case groups. The results
\end{abstract}

Correspondence to: Dr Nurten Bahtiyar, Department of Biophysics, Cerrahpasa Faculty of Medicine, Istanbul University, 53 Kocamustafa Pasa Street, Fatih, 34098 Istanbul, Turkey

E-mail: nurtenbahtiyar@hotmail.com

Key words: platelets, type 2 diabetes mellitus, mitochondrial DNA4977 deletion, mitochondrial membrane potential, adenosine 5'-triphosphate/adenosine 5'-diphosphate, P-selectin indicated that the $\mathrm{mtDNA}^{4977}$ deletion occurred in platelets, and increased deletion in patients with type 2 diabetes did not have a marked influence on mitochondrial and/or platelet dysfunction, when compared with the non-diabetic subjects. Further research is required to elucidate the sources of inter-individual variability observed in certain parameters.

\section{Introduction}

Diabetes mellitus is one of the principal risk factors for the development of vascular complications. Several studies have highlighted the involvement of platelets, as a component of the coagulation system, in the development of vasculopathies, which is a multifactorial process (1-3). Individuals with type 2 diabetes mellitus may also be characterized by a high incidence of blood platelet dysfunction $(4,5)$.

As the energy produced by mitochondria is required for fundamental processes of platelet functioning, platelet mitochondria may be regarded as a factor for the development of disorders of platelet adhesion and aggregation and vasculopathies in diabetes mellitus. However, the potential involvement of platelet mitochondria in mechanisms underlying these dysfunctions remains unclear. In platelets, which are anucleated cells, the mitochondria are the primary source of adenosine 5 -triphosphate (ATP) production from acetyl-coenzyme A oxidation and oxidative phosphorylation $(6,7)$. Adenine nucleotides are required for platelet activation and aggregation, and for platelet bioenergetic maintenance $(1,6,8)$. It has been established that ATP itself or its breakdown to adenosine 5'-diphosphate (ADP) may activate platelets (8). In addition, intracellular ADP and ATP levels have an essential role in blood platelet activation though the regulation of intracellular calcium (9).

A number of reports have indicated that hyperglycemia may increase reactive oxygen species production and subsequent oxidative stress (10-12). In addition, hyperglycemia-induced oxidative stress is a principal contributor to mitochondrial damage in cells (13). Although the majority of mitochondrial 
proteins are encoded by the nuclear genome, numerous important proteins involved in oxidative phosphorylation are encoded by mitochondrial DNA (mtDNA) such as NADH dehydrogenase 1 , cytochrome b, cytochrome c oxidase I and ATP synthase 6 . Increased oxidative stress reduces ability to repair and histone protection, which affects the mitochondria and damages mtDNA. Once the proportion of mutated mtDNA rises above a threshold, mitochondrial membrane potential $(\Delta \Psi \mathrm{m})$, mitochondrial ATP synthesis and the cellular ATP/ADP ratio decrease. If ATP demands are not met, this may increase the risk of a number of pathologies, including cell death and organ failure, are known to be associated with disease or aging (14).

At least 20 different types of deletions in mtDNA have been documented to accumulate in aging human tissues (15). Among these deletions, a common marker of mtDNA damage associated with oxidative stress is the 4,977-base pair (bp) common deletion (mtDNA $\left.{ }^{4977}\right)(16)$. The deleted mtDNA for this mutation contains all or part of the genes encoding four polypeptides for complex I, one for complex IV, two for complex $\mathrm{V}$ involved in oxidative phosphorylation, and five tRNA genes. It has been demonstrated that the mtDNA ${ }^{4977}$ deletion is associated with metabolic machinery defects that are acquired during aging. Furthermore, there may be a correlation between an accumulation of mtDNA ${ }^{4977}$ deletions and reduced ATP production in a number of tissues $(14,17)$.

The mtDNA ${ }^{4977}$ deletion accumulates faster in tissues with greater metabolic activity and minimal cell turnover, including those in the brain and heart (18). Elevated levels of these deletions have also been detected in peripheral leucocytes, which have a high turnover activity, from patients with a variety of diseases associated with oxidative stress, including type 2 diabetes mellitus (18). The frequency of mtDNA ${ }^{4977}$ deletions may be elevated in platelets, as well as whole blood cells, in response to increased oxidative damage in diabetes mellitus. This may result in bioenergetic impairment and platelet functional alteration. To the best of the authors' knowledge, the frequency and proportion of deleted mtDNA has not yet been detected in the platelets of patients with type 2 diabetes mellitus.

Taking these previous findings into account, the aim of the present study was to assess the mitochondrial common deletion in the platelets of patients with type 2 diabetes mellitus, in the context of mitochondrial function and platelet reactivity. To make this assessment, the mtDNA ${ }^{4977}$ deletion frequency, mtDNA copy number, $\Delta \Psi \mathrm{m}$, adenine nucleotide level and P-selectin (CD62p) expression was measured in the peripheral blood platelets of patients with type 2 diabetes, with and without complications. The obtained findings were compared with data from age- and body mass index (BMI)-matched healthy control subjects. Data presented indicate that the mtDNA $^{4977}$ deletion occurred in platelets more frequently in patients with diabetes and that there is a requirement for further studies to explore its clinical significance.

\section{Materials and methods}

Study population and collection of specimens. The present study was conducted on outpatients receiving anti-diabetic treatment at the Istanbul Training and Research Hospital
(Istanbul, Turkey) between June 2015 and February 2016. This study included 66 patients (31 men, 35 women) with diabetes and 23 (13 men, 10 women) age- and BMI-matched healthy subjects. Patients with type 2 diabetes mellitus were divided into three groups based on plasma glycated hemoglobin (HbAlc) levels, and the presence or absence of chronic diabetic complications: Group I, good glycemic control (HbAlc <7) without complications; Group II, poor glycemic control (HbA1c $\geq 7$ ) without complications; and Group III, poor glycemic control (HbAlc $\geq 7)$ with complications. The patients were evaluated for micro- and macrovascular complications via clinical and laboratory tests. Patients with diabetic complications had at least one of the following: Neuropathy, peripheral vascular disease, cerebrovascular disease, nephropathy or retinopathy.

The inclusion criteria for patients and healthy volunteers were: Age range, $45-70$ years; $\mathrm{BMI}, \geq 22 \mathrm{~kg} / \mathrm{m}^{2}$; and a history of type 2 diabetes lasting $\geq 5$ years. Exclusion criteria for the patients were: A medical history including hematological disorders that affected platelet count or function, malignant disease, hypertension, chronic inflammatory disease, infectious disease or autoimmune disease. For healthy control subjects, the exclusion criteria were: A known history of chronic, inflammatory or malignant disease, and the use of antithrombotic drugs. All patients provided written informed consent. The present study was approved by the Istanbul Training and Research Hospital Ethics Committee (approval no. 339/2013; Istanbul, Turkey), and was performed according to the criteria set out by the Declaration of Helsinki.

Platelet preparation. Platelets from peripheral blood were prepared by differential centrifugation, according to the following method: Peripheral blood $(10 \mathrm{ml})$ was collected in a vacutainer tube containing containing $3.8 \%$ sodium citrate and was processed within $30 \mathrm{~min}$ of collection. Samples were centrifuged at $160 \mathrm{xg}$ for $10 \mathrm{~min}$ at $22^{\circ} \mathrm{C}$, and the platelet-rich plasma (PRP) was carefully aspirated, leaving behind the erythrocytes, prior to centrifugation again at $160 \mathrm{x} g$ for $5 \mathrm{~min}$ at $22^{\circ} \mathrm{C}$ to remove the leukocytes. The PRP was diluted with PBS (1:1) and carefully layered onto the Histopaque-1077 (Sigma-Aldrich; Merck KGaA, Darmstadt, Germany) (2:1) for leukocyte depletion. Following centrifugation at $350 \mathrm{x} \mathrm{g}$ for $20 \mathrm{~min}$ at $22^{\circ} \mathrm{C}$, the opaque interface and the upper layer were transferred into a clean conical centrifuge tube and diluted with PBS. Subsequently, the platelet suspension was filtered with a $6-\mu \mathrm{m}$ pluriStrainer (pluriSelect Life Science, Leipzig, Germany), which was put onto a separate sterile centrifuge tube, using a connector ring to remove traces of contaminating leukocytes. Following centrifugation for $10 \mathrm{~min}$ at $1,500 \mathrm{x} \mathrm{g}$ at $22^{\circ} \mathrm{C}$, the platelet pellet was washed with PBS. The platelet counts of prepared samples were analyzed with a Cell-Dyn Coulter counter (Abbott Pharmacuetical Co. Ltd., Lake Bluff, IL, USA).

mtDNA extraction. mtDNA was isolated from washed platelets with the BioVision mitochondrial DNA isolation kit (cat. no. K280-50; BioVision, Inc., Milpitas, CA, USA). The concentration of DNA was determined with a NanoDrop ${ }^{\mathrm{TM}}$ 2000 spectrophotometer (Thermo Fisher Scientific, Inc., Waltham, MA, USA) and the samples were stored at $-80^{\circ} \mathrm{C}$ until further experimentation. 
Analysis of the amount of mtDNA and the $m t D N A^{4977} b p$ deletion by polymerase chain reaction $(P C R)$. The levels of mtDNA $^{4977}$ deletion and mitochondrial reference fragment in mtDNA isolated from platelet samples were determined by fluorescence-based quantitative (q)PCR as described previously (19-21), with certain modifications. The fragment with no deletions and the conservative region of mtDNA was taken as reference for the total mtDNA. The following primer sets were used: Normal mtDNA (mtDNA ${ }^{\mathrm{n}}$; internal control) forward, 5'-AACATACCCATGGCCAAC-3' and reverse, 5'-TCAGCGAAGGGTTGTAGTAGC-3' (249 bp); and mtDNA $^{4977}$ deletion forward, 5'-TATGGCCCACCATAA TTACCC-3' and reverse, 5'-AAGCGAGGTTGACCTGTT AGG-3' (270 bp). Purified PCR products were cloned into the pGEM-T Easy vector (Promega Corporation, Madison, WI, USA), according to the manufacturer's protocol, and dose-dependent plasmid-constructed $\left(\mathrm{mtDNA}^{\mathrm{n}}\right.$ and mtDNA $^{4977}$ ) standards were used in each run of PCR for qPCR optimization and sensitivity analysis. The plasmids were further confirmed by Sanger sequencing method using the ABI Prism 3130XL Genetic Analyzer and the BigDye Terminator v3.1 Ready Reaction Kit (Applied Biosystems; Thermo Fisher Scientific, Inc.). DNA samples were subjected to qPCR with the CFX Connect ${ }^{\mathrm{TM}}$ Real-Time PCR Detection system (Bio-Rad Laboratories, Inc., Hercules, CA, USA) beginning with an initial denaturation step at $95^{\circ} \mathrm{C}$ for $10 \mathrm{~min}$, followed by for 40 cycles of $94^{\circ} \mathrm{C}$ for $15 \mathrm{sec}$ and $60^{\circ} \mathrm{C}$ for $1 \mathrm{~min}$, using the iTaq Universal SYBR Green Supermix (Bio-Rad Laboratories, Inc.). PCR amplifications were performed in a $20-\mu 1$ reaction volume, containing 20 ng DNA template and a $10 \mathrm{nmol} / \mathrm{l}$ concentration of each primer. Average quantitation cycle $(\mathrm{Cq})$ values were calculated to determine the mtDNA content and deletion load in samples (22). Each measurement was repeated two or three times and normalized against a serial dilution of the corresponding plasmid clones at a known concentration. The quantity of each target gene in the samples was subsequently calculated according to the corresponding standard curve. The formula published by the Genomics and Sequencing Center of the University of Rhode Island (Kingston, RI, USA; cels.uri.edu/gsc/cndna. html) was used to calculate the mtDNA copy number. The formula used was: Number of copies $=($ amount of DNA $\left.\mathrm{x} 6.022 \times 10^{23}\right) /\left(\right.$ length of amplicon $\left.\mathrm{x} 1 \times 10^{9} \times 650\right)$. The level of mtDNA $^{4977}$ deletion was expressed as a percentage ratio of the deleted mtDNA copy number with respect to the total mtDNA copy number.

$A T P / A D P$ assay. Frozen platelet cell samples were rapidly thawed and the cell debris was pelleted by centrifugation (10,000 x g for $3 \mathrm{~min}$ at room temperature). The supernatant was diluted in $3 \%$ perchloric acid. Samples were subsequently neutralized with $75 \mu \mathrm{l}$ ice-cold $2 \mathrm{M} \mathrm{KOH}, 2 \mathrm{mM} \mathrm{Na}{ }_{2}$ EDTA, $50 \mathrm{mM}$ 3-(N-morpholino)propanesulfonic acid, which was incubated on ice for $10 \mathrm{~min}$. The precipitate was pelleted by centrifugation $(10,000 \mathrm{x}$ g for $1 \mathrm{~min}$ at room temperature) and the ADP/ATP levels of the supernatant were determined using the EnzyLight ADP/ATP Ratio Assay kit (BioAssay Systems, Hayward, CA, USA), according to the manufacturer's protocol, by comparison with the appropriate standards. Protein concentrations in samples were determined using the Bio-Rad DC ${ }^{\text {TM }}$
Protein Assay kit (Bio-Rad Laboratories, Inc.) and ADP/ATP content was expressed as nmol/mg protein.

$\Delta \Psi_{m}$ assay. $\Delta \Psi \mathrm{m}$ was assessed using a JC-10 fluorometric assay kit (AAT Bioquest, Inc., Sunnyvale, CA, USA) according to the manufacturer's protocol. JC-10 dye loading solution $(20 \mu \mathrm{M})$ was added to each well and cells were incubated for $30 \mathrm{~min}$ at $37^{\circ} \mathrm{C}$. Red fluorescent JC-10 aggregates were detected at $540 \mathrm{~nm}$ excitation and $590 \mathrm{~nm}$ emission. Green fluorescence due to the $\Delta \Psi \mathrm{m}$ collapse was detected at $490 \mathrm{~nm}$ excitation and $525 \mathrm{~nm}$ emission. The ratio of fluorescence intensities on emission at 525/590 was used to determine mitochondrial membrane depolarization. Data were recorded in relative fluorescence units and normalized to the total protein amount using the Bradford assay (Sigma-Aldrich; Merck KGaA). The JC-10 aggregate/monomer ratio was proportional to $\Delta \Psi \mathrm{m}$.

Flow cytometry for platelet CD62p expression. Platelet CD62p expression levels, as a marker of platelet activation, were measured under the basal and activated (with $1 \mu \mathrm{M}$ ADP; Chrono-Log Corporation, Havertown, PA, USA; for $5 \mathrm{~min}$ at room temperature) conditions by flow cytometry. Blood was collected into collection tubes containing 3.8\% sodium citrate. PRP was obtained from tube following $10 \mathrm{~min}$ of centrifugation at $160 \mathrm{x} \mathrm{g}$ at $22^{\circ} \mathrm{C}$, and $50 \mu \mathrm{l} \mathrm{PRP}$ was diluted with $450 \mu 1$ PBS ( $\mathrm{pH} 7.4$ ). A volume of $100 \mu 1$ of the mixture was incubated with fluorescein isothiocyanate (FITC)-conjugated CD62p antibodies (1:100; cat. no. 555523; BD Biosciences, San Jose, CA, USA) and phycoethryin (PE)-conjugated platelet glycoprotein IIb of IIb/IIIa complex antibodies (1:100; cat. no. 55467; BD Biosciences, San Jose, CA, USA) for $20 \mathrm{~min}$ at room temperature in the dark. As control experiments, platelets were incubated with PE-conjugated non-specific mouse immunoglobulin G1 (1:100; cat. no. 406608; BioLegend, Inc., San Diego, CA, USA). Following gentle mixing, samples were washed once in $2 \mathrm{ml} \mathrm{PBS}$ and centrifuged at 1,500 $\mathrm{x} \mathrm{g}$ for $5 \mathrm{~min}$ at $22^{\circ} \mathrm{C}$. The supernatant was discarded and samples were fixed with $1 \%$ paraformaldehyde $(500 \mu \mathrm{l})$. The fixed samples were analyzed at room temperature for up to $4 \mathrm{~h}$, and data acquisition was done by flow cytometry. Platelet populations were sorted by side-scatter (SSC) and forward scatter (FSC), and the FL1 channel detected the FITC fluorescence intensity. Data from the fluorescence-activated cell sorting process was further analyzed using WinMDI version 2.8. software (Scripps Research Institute, USA). Data were expressed as the percentage of positive events.

Statistical analysis. Differences between groups with normally distributed data were tested using one-way analysis of variance (ANOVA) followed by Tukey's post-hoc test. Kruskal-Wallis with Dunn's post-hoc test was used for non-parametric data analyses. Each experiment was repeated $\geq 2$ times, and data were expressed as the mean \pm standard deviation. $\mathrm{P} \leq 0.05$ was considered to indicate a statistically significant difference. Spearman's correlation coefficients were estimated to determine the correlation between variables. Analyses were performed using the GraphPad Prism 5.0 statistical package (GraphPad Software, Inc., La Jolla, CA, USA). Cv values were calculated as: $\% \mathrm{Cv}=$ (standard deviation of measurement/measurement average) x100. 
Table I. Clinical characteristics and laboratory data of patients with diabetes and healthy subjects.

\begin{tabular}{lcccc}
\hline Clinical characteristics & Group I & Group II & Group III & Healthy subjects \\
\hline Subjects, $\mathrm{n}$ & 20 & 20 & 26 & 23 \\
Age, years & $59.14 \pm 7.83$ & $58.61 \pm 7.49$ & $60.27 \pm 7.29$ & $58.38 \pm 6.82$ \\
Sex, male/female & $9 / 11$ & $8 / 12$ & $14 / 12$ & $13 / 10$ \\
BMI, kg/m & $25.11 \pm 2.80$ & $25.85 \pm 2.27$ & $26.15 \pm 2.55$ & $24.95 \pm 2.65$ \\
Diabetic duration, years & $7.51 \pm 1.62^{\mathrm{a}}$ & $9.45 \pm 2.24^{\mathrm{c}}$ & $11.31 \pm 3.81^{\mathrm{d}}$ & $\mathrm{N} / \mathrm{A}$ \\
Fasting plasma glucose, mg/dl & $118 \pm 10^{\mathrm{b}, \mathrm{e}}$ & $144 \pm 25^{\mathrm{c}, \mathrm{e}}$ & $162 \pm 35^{\mathrm{d}, \mathrm{e}}$ & $85 \pm 7$ \\
HbA1c, $\%$ & $5.96 \pm 0.74^{\mathrm{b}, \mathrm{e}}$ & $7.88 \pm 0.70^{\mathrm{c}, \mathrm{e}}$ & $9.27 \pm 1.20^{\mathrm{d}, \mathrm{e}}$ & $5.07 \pm 0.59$ \\
\hline
\end{tabular}

Data are presented as the mean \pm standard deviation. ${ }^{\text {a }}<0.01$ vs. group II; ${ }^{\mathrm{P}} \mathrm{P}<0.001$ vs. group II; ${ }^{\mathrm{c}} \mathrm{P}<0.001 \mathrm{vs}$. group III; ${ }^{\mathrm{d}} \mathrm{P}<0.001 \mathrm{vs}$. group I; ${ }^{\mathrm{e}} \mathrm{P}<0.001$ vs. healthy subjects. Group I, good glycemic control (HbA1c $<7$ ) without complications; Group II, poor glycemic control (HbA1c $\geq 7$ ) without complications; Group III, poor glycemic control (HbA1c $\geq 7$ ) with complications.

\section{Results}

Clinical and laboratory characteristics among the studied groups with type 2 diabetes. Clinical characteristics and laboratory data of patients with type 2 diabetes mellitus and healthy subjects are presented in Table I. Age, sex, BMI, diabetic duration, fasting plasma glucose and $\mathrm{HbAlc}$ values were used as a clinical characteristic parameters for patients and healthy subjects. No significant differences were observed in the age and BMI values among the patient and control groups $(\mathrm{P}>0.05)$. Fasting plasma glucose levels in type 2 diabetic patients in groups II and III were significantly increased compared with those in group I (HbAlc $<7$; $\mathrm{P}<0.001)$. In addition, the fasting plasma glucose levels of all patient groups were significantly increased compared with the control group $(\mathrm{P}<0.001)$. HbA1c values in type 2 diabetic patients in groups II and III were significantly higher compared with group I $(\mathrm{P}<0.001)$. All patient groups had significantly higher HbAlc values, compared with those in the control group $(\mathrm{P}<0.001)$.

$m t D N A^{4977}$ bp deletion and mtDNA copy number in the blood platelets of patients with type 2 diabetes. A qPCR assay was performed in order to measure the frequency of mtDNA ${ }^{4977}$ deletion. This mutation was detected in all examined platelet samples, with the exception of two diabetic patients and one non-diabetic subject. Although the mtDNA ${ }^{4977}$ carriers were identified at a similar frequency in patients with type 2 diabetes mellitus (96.9\%) and controls (95.6\%), the level of mtDNA ${ }^{4977}$ deletion was higher in each of the three patient groups, compared with the control group (Fig. 1), as demonstrated using the Kruskal-Wallis test and Dunn's multiple comparison test. However, the levels did not differ significantly among the three subgroups of the patients.

Notably, the coefficient of variation (CV) value for mtDNA $^{4977}$ deletion/mtDNA copy number was higher in the healthy control group, compared with the patient groups (group I, 48\%; group II, 59\%; group III, 43\%; and control group, $75 \%$ ). Differences in mitochondrial DNA copy number were not observed in platelets among the groups. However, the range of $\mathrm{CV}$ values observed in the patient groups was larger (76-102\%; Fig. 2).

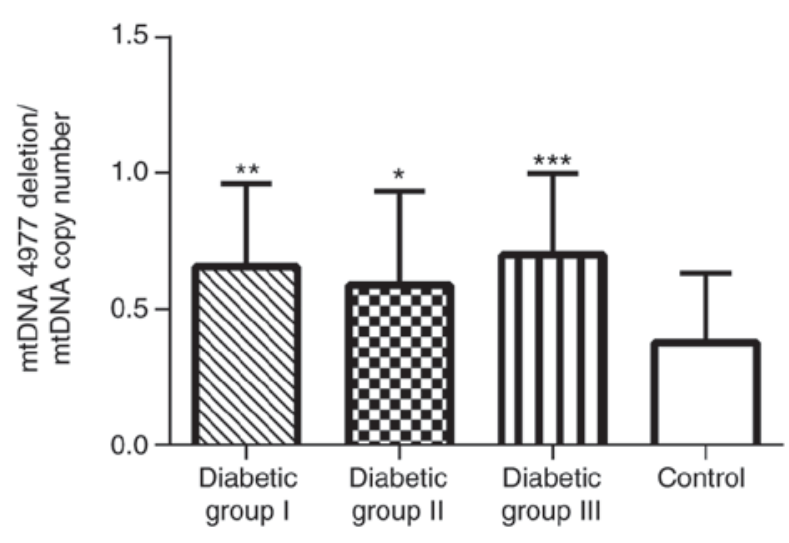

Figure 1. Comparison of mtDNA deletion frequency (\%) in the platelets of patients with type 2 diabetes and healthy subjects. Data were analyzed with Kruskal-Wallis, followed by Dunn's post-hoc test correction in the GraphPad Prism package, and are expressed as the mean \pm standard deviation. ${ }^{*} \mathrm{P}<0.05$, ${ }^{* * *} \mathrm{P}<0.01,{ }^{* * *} \mathrm{P}<0.001$ vs. control. mtDNA, mitochondrial DNA; group I, good glycemic control (HbA1c $<7$ ) without complications; group II, poor glycemic control (HbAlc $\geq 7$ ) without complications; group III, poor glycemic control (HbAlc $\geq 7$ ) with complications.

ATP/ADP levels in platelets. As presented in Table II, no significant differences in platelet ATP and ADP content were observed among the groups $(\mathrm{P}>0.05)$. In addition, relative ATP/ADP content was similar among the groups. However, the CV values of the ATP levels were $~ 90 \%$ for group III.

JC-10 assay. $\Delta \Psi \mathrm{m}$ was measured as a marker of mitochondrial bioenergetic efficiency, in addition to ATP. JC-10 is a sensitive cationic and lipophilic fluorescent probe that was used to monitor $\Delta \Psi \mathrm{m}$ alterations in platelets. The results revealed that there were no significant differences in the patient groups, compared with the control group $(\mathrm{P}>0.05$; Fig. 3).

Expression of CD62p. The level of basal platelet activation was measured by detecting the expression of surface platelet marker, CD62p. The level of blood platelet responsiveness to ADP $(1 \mu \mathrm{M})$ was also measured. The percentage of CD62 $\mathrm{p}^{+}$ platelets was not significantly different among the four groups (P $>0.05$; Fig. 4A). Furthermore, no significant differences 
Table II. Adenine nucleotide content in resting platelets of patients with type 2 diabetes and healthy subjects.

\begin{tabular}{lcccc}
\hline Measure & Group I $n=20$ & Group II $n=20$ & Group III $n=26$ & Healthy subjects n=23 \\
\hline ATP (nmol/mg platelet protein) & $22.13 \pm 12.92$ & $24.70 \pm 14.90$ & $19.95 \pm 18.05$ & $26.98 \pm 11.78$ \\
ADP (nmol/mg platelet protein) & $14.46 \pm 8.04$ & $15.33 \pm 8.52$ & $13.17 \pm 5.97$ & $17.04 \pm 7.89$ \\
ATP/ADP & $1.56 \pm 0.37$ & $1.61 \pm 0.37$ & $1.53 \pm 0.42$ & $1.61 \pm 0.32$ \\
\hline
\end{tabular}

Values are presented as the mean \pm standard deviation. ${ }^{a}$ The values of ATP/ADP ratio are mean \pm standard deviation of all patients in the group. ATP, adenosine 5'-triphosphate; ADP, adenosine 5'-diphosphate; group I, good glycemic control (HbA1c <7) without complications; group II, poor glycemic control (HbA1c $\geq 7$ ) without complications; group III, poor glycemic control (HbA1c $\geq 7$ ) with complications.



Figure 2. Comparison of mtDNA copy number in platelets from patients with type 2 diabetes and healthy subjects. Mean mtDNA content was compared by one-way analysis of variance. mtDNA content was not significantly different among the groups. mtDNA, mitochondrial DNA; group I, good glycemic control (HbA1c <7) without complications; group II, poor glycemic control (HbAlc $\geq 7$ ) without complications; group III, poor glycemic control (HbA1c $\geq 7$ ) with complications.

in the percentage of CD62p expression on ADP-activated platelets was observed between the patient groups and healthy control subjects (ANOVA; P>0.05; Fig. 4B).

Associations between mtDNA 4977 deletion and other studied parameters. To better characterize the consequences of increased $\mathrm{mtDNA}^{4977}$ deletion in platelets, the potential associations between this parameter and other bioenergetics parameters were studied, including platelet activation marker expression and mtDNA copy number. Simple correlation analyses demonstrated that the deletion level was positively correlated with mtDNA copy number in patients with complications (Table III). However, no significant correlations were detected between the accumulation of $\mathrm{mtDNA}^{4977}$ and with the other studied parameters in patient groups.

\section{Discussion}

There is experimental evidence that hyperglycemia-induced oxidative stress may markedly decrease the mutation threshold required for mitochondrial dysfunction (23). Additionally, a number of reports have suggested that an increased mtDNA mutation rate in various cell types, including the skeletal muscle, kidney and pancreas, is associated with diabetes mellitus (24-26). Furthermore, it has been reported that mitochondrial dysfunction occurs with increased accumulation of

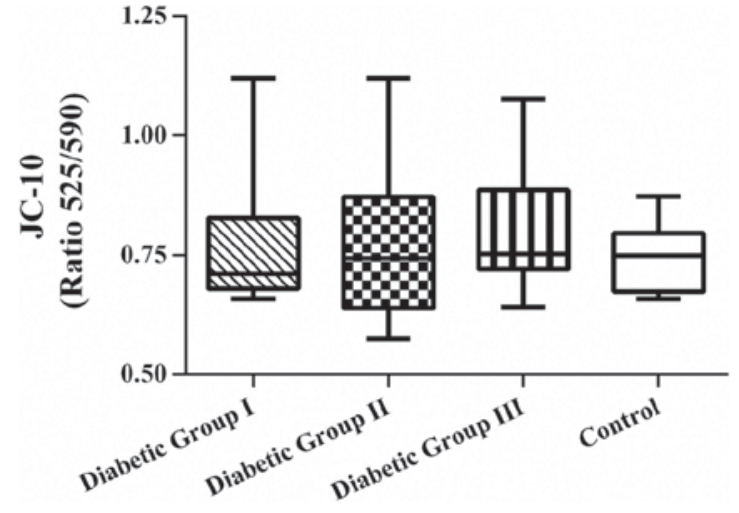

Figure 3. Comparison of $\Delta \Psi \mathrm{m}$ in platelets from patients with type 2 diabetes and healthy subjects. $\Delta \Psi \mathrm{m}$ was determined by a JC-10 assay and mean values were compared by one-way analysis of variance. $\Delta \Psi \mathrm{m}$ did not differ between groups. $\Delta \Psi \mathrm{m}$, mitochondrial membrane potential; group I, good glycemic control (HbAlc <7) without complications; group II, poor glycemic control (HbA1c $\geq 7$ ) without complications; group III, poor glycemic control (HbA1c $\geq 7$ ) with complications.

various mtDNA mutations, including $\mathrm{mtDNA}^{4977}$, in the peripheral blood mononuclear cells of patients with diabetes (18). Over the lifetime of an organism, nuclear and mitochondrial mutations tend to accumulate in adult stem cells, including bone marrow stem cells (27). Therefore, mtDNA ${ }^{4977}$ deletion, a common mutation of the mitochondrial genome, is expected to be at a high frequency in platelets, which derived from megakaryocytes, with a shorter lifespan as well as in blood stem cells.

As hyperglycemia may be a risk factor for increased mitochondrial mutation accumulation in stem cells, it was hypothesized that the mtDNA ${ }^{4977}$ deletion may have accumulated in the platelets of patients with diabetes. In the present study, it was demonstrated that mtDNA ${ }^{4977}$ was accumulated in peripheral blood platelets in the majority of cases. Furthermore, the accumulation of the mtDNA ${ }^{4977}$ deletion was more pronounced in the platelets of patients with type 2 diabetes compared with healthy subjects. To the best of the authors' knowledge, this is the first study to suggest a potential link between the mtDNA ${ }^{4977}$ deletion and diabetes, specifically in platelets.

The present data suggested that there was 50-75\% interindividual variability in the levels of mtDNA4977 deletion in patients with diabetes and healthy subjects. The findings provided further evidence that the mtDNA ${ }^{4977}$ deletion may be common in the population, as demonstrated in previous studies 
Table III. Correlations between mtDNA ${ }^{4977}$ deletion and the other detected parameters in each diabetes subgroup.

\begin{tabular}{llll}
\hline Parameter & \multicolumn{1}{c}{ Group I } & \multicolumn{1}{c}{ Group II } & Group III \\
\hline ATP vs. mtDNA ${ }^{4977}$ deletion & $\mathrm{P}=0.662, \mathrm{r}=-0.214$ & $\mathrm{P}=0.632, \mathrm{r}=-0.176$ & $\mathrm{P}=0.528, \mathrm{r}=0.203$ \\
mtDNA copy number vs. mtDNA $^{4977}$ deletion & $\mathrm{P}=0.925, \mathrm{r}=0.024$ & $\mathrm{P}=0.714, \mathrm{r}=0.087$ & $\mathrm{P}=0.274, \mathrm{r}=0.223$ \\
$\Delta \Psi$ m vs. mtDNA ${ }^{4977}$ deletion & $\mathrm{P}=0.200, \mathrm{r}=-0.571$ & $\mathrm{P}=0.296, \mathrm{r}=0.370$ & $\mathrm{P}=0.362, \mathrm{r}=0.275$ \\
${\text { P-selectin with ADP stimulation vs. } \text { mtDNA }^{4977} \text { deletion }}^{\mathrm{P}=0.662, \mathrm{r}=-0.264}$ & $\mathrm{p}=0.470, \mathrm{r}=0.261$ & $\mathrm{P}=0.793, \mathrm{r}=-0.082$
\end{tabular}

mtDNA, mitochondrial DNA; ATP, adenosine 5'-triphosphate; ADP, adenosine 5'-diphosphate; $\Delta \Psi \mathrm{m}$, mitochondrial membrane potential; group I, good glycemic control (HbA1c <7) without complications; group I, good glycemic control (HbA1c <7) without complications; group II, poor glycemic control (HbA1c $\geq 7$ ) without complications; group III, poor glycemic control (HbA1c $\geq 7$ ) with complications.


Figure 4. Expression of CD62p as the percentage of CD62p-positive platelets in (A) resting and (B) ADP-activated platelets in patients with type 2 diabetes and the control group. Mean values were compared by one-way analysis of variance and did not differ between groups. CD62p, P-selectin; CD41a, platelet glycoprotein IIb of IIb/IIIa complex; ADP, adenosine 5'-diphosphate; group I, good glycemic control (HbA1c <7) without complications; group II, poor glycemic control (HbAlc $\geq 7$ ) without complications; group III, poor glycemic control (HbAlc $\geq 7$ ) with complications.

of numerous cell types, including human leukocytes $(18,19,24)$. Numerous factors may contribute to the variability in the level of mtDNA deletion in platelets. According to simple correlation analysis, age, which was among the candidate causative factors for this interindividual variation, was not responsible for the mtDNA ${ }^{4977}$ deletion level in the present study (data not shown). This result was consistent with a similar observation in the platelets of non-medicated patients with early Parkinson's disease, age-matched healthy controls and young subjects by Sandy et al (28). In contrast to our data, Biagini et al (29) did not detect this deletion in platelets obtained from both young and old individuals. On the other hand, these studies may have a potential contamination of platelet samples with other cellular components of blood. In addition, it is noteworthy that the amount the mtDNA ${ }^{4977}$ bp deletion in the study of Biagini et al (29) has been detected by semi-quantitative PCR. Evidence from human and animal studies demonstrates that abnormal circulating platelet reactivity typically occurs in pathological states associated with diabetes mellitus (30-32). Studies have proposed a number of mechanisms concerning this phenomenon, including abnormalities in mitochondrial respiration and altered adenine nucleotide metabolism $(6,8,33,34)$. Although ADP is the principal promoter of platelet aggregation, previous reports indicate that ATP contributes to platelet activation $(35,36)$. Additionally, it has been revealed that abnormal platelet reactivity occurs in patients with diabetes mellitus (8).
The high level of mtDNA ${ }^{4977}$ deletion in platelets raises the possibility of reduced ATP production in platelets, as a previous study indicated that ATP synthesis declines in cells as $\mathrm{mtDNA}^{4977}$ deletion frequency increases (14). However, the exact effects of mtDNA deletion remain unclear. Given the lack of specific literature on this topic, it may be important to evaluate whether the increase in $\mathrm{mtDNA}^{4977}$ deletions observed in the platelets of patients with diabetes consequently affects platelet mitochondrial function and reactivity.

In addition, it was hypothesized that a higher frequency of mtDNA ${ }^{4977}$ deletions in the platelets of patients with diabetes was associated with abnormal platelet mitochondrial function. In the present study, no platelet mitochondrial dysfunction differences were observed between patients with type 2 diabetes and healthy subjects, as platelet adenine nucleotide content and $\Delta \Psi \mathrm{m}$ were similar between the two groups. Furthermore, the results of basal platelet activation and platelet responsiveness to ADP by platelet P-selectin expression demonstrated that the accumulation of mtDNA ${ }^{4977}$ deletion in platelets of diabetic patients was not accompanied by abnormal platelet reactivity. Furthermore, correlations between the mtDNA ${ }^{4977}$ deletion and the studied parameters were not identified, suggesting that the increased platelet mtDNA ${ }^{4977}$ deletion may not have had a major role in mitochondrial and platelet function. Inconsistent results have been reported in the literature concerning blood platelet mitochondrial activity, in which increased (32), reduced (37) and unaltered (38) mitochondrial 
function has been demonstrated in diabetes. There is evidence that platelet function abnormalities are multifactorial, although it is not clear whether platelet abnormalities are intrinsic to the platelet or are a consequence of circulating factors that affect platelet function. Undoubtedly, these discrepancies may be due to numerous reasons, including differences in participant selection, disease stage, treatment type and measuring techniques $(39,40)$. For example, a report demonstrated that there were no abnormalities in platelet function in patients with moderately controlled type 2 diabetes (41). Due to these and other potential variables, comparisons among studies are difficult. Mitochondria are dynamic organelles, and mtDNA copy number generally varies depending on the energy demand of the cell or tissue. Alterations have been observed in a variety of pathologies and in the presence of various environmental stressors, such as diabetes, hypoxia and oxidative stress $(42,43)$. Additionally, a number of previous studies on different human tissues suggested that higher mtDNA content may be involved in a protective mechanism against damage induced by such stressors to regulate energy balance (44). Considering the lack of association between increased mtDNA ${ }^{4977}$ deletion and ATP/ADP levels in platelets from the diabetic patients compared with healthy subjects, mtDNA copy number analysis was also performed to evaluate whether mtDNA content had a compensatory role in response to diabetes. Although mtDNA content in platelets was lower in the good glycemic control group compared with the other groups, the results revealed that the differences were not statistically significant. As Tang et al (37) reported that the copy number is significantly higher in various cell and cell lines, including fibroblasts, due to $\mathrm{mtDNA}^{4977}$ deletion accumulation, the present study evaluated the correlation between mtDNA ${ }^{4977}$ deletion frequency and mtDNA copy number in platelets, using Spearman's correlation coefficient. However, no correlations were observed between the mtDNA ${ }^{4977}$ deletion frequency and mtDNA copy number in each diabetic group, suggesting that increased mitochondrial deletion in platelets had not induced mtDNA copy number alterations, as a compensatory effect in response to mtDNA deletion.

According to prior calculations, there would have to be 17 participants in each study group in order to detect a difference of 0.8 (80\% power and 5\% significance level). However, the post-hoc power calculations based on the available data indicated that the present study had a lower power for mtDNA 4977 deletion, mtDNA copy number and ATP levels due to large interindividual variation. Therefore, it was concluded that the analyses would gain credibility if they were performed using data from a larger sample.

The findings of the present study demonstrated that the mtDNA $^{4977}$ deletion occurred in platelets more frequently in patients with diabetes, compared with healthy donors, although mtDNA ${ }^{4977}$ deletion levels were not associated with glycemic control or the presence of diabetic complications. Accumulation of $\mathrm{mtDNA}^{4977}$ deletion in the platelets of diabetic patients did not appear to have a significant impact on mitochondrial and/or platelet dysfunction when compared with nondiabetic subjects. Furthermore, no differences in mtDNA copy number between the diabetic groups and control group were noted, suggesting copy number did not have a compensatory role in energy balance regulation. Further studies are required in order to understand the sources of inter-individual variability observed in certain parameters.

\section{Acknowledgements}

The authors would like to thank Mr. Burhan Çağçağ (Tissue Typing Laboratory, Cerrahpasa Faculty of Medicine, Istanbul University, Turkey) for his technical assistance.

\section{Funding}

The present study was supported by The Turkish Society of Hematology (grant no. 2015-4).

\section{Availability of data and materials}

The datasets used and/or analyzed during the present study are available from the corresponding author on reasonable request.

\section{Authors' contributions}

AK, YH, İO, MN and NB were responsible for study conception and design. $\mathrm{YH}$ and $\mathrm{MN}$ provided the patient specimens. AK, NB, İO, FA, EY and TU performed data analysis. AK, YH, NB, MN, İ, FA, EY and TU performed data interpretation. All authors approved the final version of this manuscript.

\section{Ethics approval and consent to participate}

The present study was approved by the Ethics Committee of the Istanbul Training and Research Hospital (Grant no. 339/2013), and informed consent to participate in the study was obtained from all patients involved.

\section{Patient consent for publication}

No identifying patient information is included in the published manuscript. Participants provided their consent for the publication of the data.

\section{Competing interests}

All the authors declare that they have no competing interests.

\section{References}

1. Smyth SS, McEver RP, Weyrich AS, Morrell CN, Hoffman MR, Arepally GM, French PA, Dauerman HL and Becker RC; 2009 Platelet Colloquium Participants: Platelet functions beyond hemostasis. J Thromb Haemost 7: 1759-1766, 2009.

2. Salem MA, Adly AA, Ismail EA, Darwish YW and Kamel HA: Platelets microparticles as a link between micro-and macro-angiopathy in young patients with type 1 diabetes. Platelets 26: 682-688, 2015.

3. Zhao LS, Lin YY, Liu Y, Xu CY, Liu Y, Bai WW, Tan XY, Li DZ and $\mathrm{Xu}$ JL: Doxazosin attenuates renal matrix remodeling mediated by anti- $\alpha_{1}$-adrenergic receptor antibody in a rat model of diabetes mellitus. Exp Ther Med 14: 2543-2553, 2017.

4. Vinik AI, Erbas T, Park TS, Nolan R and Pittenger GL: Platelet dysfunction in type 2 diabetes. Diabetes Care 24: 1476-1485, 2001.

5. Sobel BE and Schneider DJ: Platelet function, coagulopathy, and impaired fibrinolysis in diabetes. Cardiol Clin 22: 511-526, 2004. 
6. Michno A, Skibowska A, Raszeja-Specht A, Cwikowska J and Szutowicz A: The role of adenosine triphosphate citrate lyase in the metabolism of acetyl coenzyme a and function of blood platelets in diabetes mellitus. Metabolism 53: 66-72, 2004.

7. Skibowska A, Raszeja-Specht A and Szutowicz A: Platelet function and acetyl-coenzyme A metabolism in type 1 diabetes mellitus. Clin Chem Lab Med 41: 1136-1143, 2003.

8. Michno A, Bielarczyk H, Pawełczyk T, Jankowska-Kulawy A, Klimaszewska J and Szutowicz A: Alterations of adenine nucleotide metabolism and function of blood platelets in patients with diabetes. Diabetes 56: 462-467, 2007.

9. Daniel JL, Dangelmaier C, Jin J, Kim YB and Kunapuli SP: Role of intracellular signaling events in ADP-induced platelet aggregation. Thromb Haemost 82: 1322-1326, 1999

10. Rolo AP and Palmeira CM: Diabetes and mitochondrial function: Role of hyperglycemia and oxidative stress. Toxicol Appl Pharmacol 212: 167-178, 2006.

11. Forbes JM, Coughlan MT and Cooper ME: Oxidative stress as a major culprit in kidney disease in diabetes. Diabetes 57 : 1446-1454, 2008.

12. Jay D, Hitomi $\mathrm{H}$ and Griendling KK: Oxidative stress and diabetic cardiovascular complications. Free Radic Biol Med 40: 183-192, 2006

13. Yamagishi SI, Edelstein D, Du XL and Brownlee $\mathrm{M}$ : Hyperglycemia potentiates collagen-induced platelet activation through mitochondrial superoxide overproduction. Diabetes 50: 1491-1494, 2001.

14. Porteous WK, James AM, Sheard PW, Porteous CM, Packer MA, Hyslop SJ, Melton JV, Pang CY, Wei YH and Murphy MP: Bioenergetic consequences of accumulating the common 4977-bp mitochondrial DNA deletion. Eur J Biochem 257: 192-201, 1998.

15. Wei YH: Oxidative stress and mitochondrial DNA mutations in human aging. Proc Soc Exp Biol Med 217: 53-63, 1998.

16. Krishnan KJ, Greaves LC, Reeve AK and Turnbull DM: Mitochondrial DNA mutations and aging. Ann N Y Acad Sci 1100: 227-240, 2007.

17. Drew B and Leeuwenburgh C: Ageing and subcellular distribution of mitochondria: Role of mitochondrial DNA deletions and energy production. Acta Physiol Scand 182: 333-341, 2004.

18. Botto N, Berti S, Manfredi S, Al-Jabri A, Federici C, Clerico A, Ciofini E, Biagini A and Andreassi MG: Detection of mtDNA with 4977 bp deletion in blood cells and atherosclerotic lesions of patients with coronary artery disease. Mutat Res 570: 81-88, 2005.

19. Lee HC, Pang CY, Hsu HS and Wei YH: Differential accumulations of 4,977 bp deletion in mitochondrial DNA of various tissues in human ageing. Biochim Biophys Acta 1226: 37-43 1994.

20. Chuanzhong Y, Ming G, Fanglin Z, Haijiao C, Zhen L, Shiping C and YongKang Z: Real-time quantitative reverse transcription-PCR assay for renal cell carcinoma-associated antigen G250. Clin Chim Acta 318: 33-40, 2002.

21. Pushnova EA, Geier M and Zhu YS: An easy and accurate agarose gel assay for quantitation of bacterial plasmid copy numbers. Anal Biochem 284: 70-76, 2000.

22. Livak KJ and Schmittgen TD: Analysis of relative gene expression data using real-time quantitative PCR and the 2(-Delta Delat C(T)) method. Methods 25: 402-408, 2001.

23. FiorentinoTV,PriolettaA,ZuoPandFolliF:Hyperglycemia-induced oxidative stress and its role in diabetes mellitus related cardiovascular diseases. Curr Pharm Des 19: 5695-5703, 2013.

24. Liang P, Hughes V and Fukagawa NK: Increased prevalence of mitochondrial DNA deletions in skeletal muscle of older individuals with impaired glucose tolerance: Possible marker of glycemic stress. Diabetes 46: 920-923, 1997.

25. Kakimoto M, Inoguchi T, Sonta T, Yu HY, Imamura M, Etoh T, Hashimoto T and Nawata H: Accumulation of 8-hydroxy-2'-deoxyguanosine and mitochondrial DNA deletion in kidney of diabetic rats. Diabetes 51: 1588-1595, 2002.
26. Lu H, Koshkin V, Allister EM, Gyulkhandanyan AV and Wheeler MB: Molecular and metabolic evidence for mitochondrial defects associated with beta-cell dysfunction in a mouse model of type 2 diabetes. Diabetes 59: 448-459, 2010.

27. Yao YG, Ellison FM, McCoy JP, Chen J and Young NS Age-dependent accumulation of mtDNA mutations in murine hematopoietic stem cells is modulated by the nuclear genetic background. Hum Mol Genet 16: 286-294, 2007.

28. Sandy MS, Langston JW, Smith MT and Di Monte DA: PCR analysis of platelet mtDNA: Lack of specific changes in Parkinson's disease. Mov Disord 8: 74-82, 1993.

29. Biagini G, Pallotti F, Carraro S, Sgarbi G, Pich MM, Lenaz G, Anzivino F, Gualandi G and Xin D: Mitochondrial DNA in platelets from aged subjects. Mech Ageing Dev 101: 269-275, 1998.

30. Tschoepe D, Roesen P, Esser J, Schwippert B, Nieuwenhuis HK, Kehrel B and Gries FA: Large platelets circulate in an activated state in diabetes mellitus. Semin Thromb Hemost 17: 433-438, 1991.

31. Watala C: Blood platelet reactivity and its pharmacological modulation in (people with) diabetes mellitus. Curr Pharm Des 11: 2331-2365, 2005.

32. Siewiera K, Kassassir H, Talar M, Wieteska L and Watala C: Higher mitochondrial potential and elevated mitochondrial respiration are associated with excessive activation of blood platelets in diabetic rats. Life Sci 148: 293-304, 2016.

33. Wu F, Liu Y, Luo L, Lu Y, Yew DT, Xu J and Guo K: Platelet mitochondrial dysfunction of DM rats and DM patients. Int J Clin Exp Med 8: 6937-6946, 2015.

34. Avila C, Huang RJ, Stevens MV, Aponte AM, Tripodi D, Kim KY and Sack MN: Platelet mitochondrial dysfunction is evident in type 2 diabetes in association with modifications of mitochondrial anti-oxidant stress proteins. Exp Clin Endocrinol Diabetes 120: 248-251, 2012

35. Rolf MG, Brearley CA and Mahaut-Smith MP: Platelet shape change evoked by selective activation of $\mathrm{P} 2 \mathrm{X} 1$ purinoceptors with alpha, beta-methylene ATP. Thromb Haemost 85: 303-308, 2001.

36. Oury C, Toth-Zsamboki E, Thijs C, Tytgat J, Vermylen J and Hoylaerts MF: The ATP-gated P2X1 ion channel acts as a positive regulator of platelet responses to collagen. Thromb Haemost 86: 1264-1271, 2001.

37. Tang Y, Schon EA, Wilichowski E, Vazquez-Memije ME, Davidson E and King MP: Rearrangements of human mitochondrial DNA (mtDNA): New insights into the regulation of mtDNA copy number and gene expression. Mol Biol Cell 11: 1471-1485, 2000.

38. Fink BD, Herlein JA, O'Malley Y and Sivitz WI: Endothelial cell and platelet bioenergetics: Effect of glucose and nutrient composition. PLoS One 7: e39430, 2012.

39. Bray PF: Platelet hyperreactivity: Predictive and intrinsic properties. Hematol Oncol Clin North Am 21: 633-645, 2007.

40. O'donnell CJ,Larson MG, Feng D, Sutherland PA, Lindpaintner K, Myers RH, D'Agostino RA, Levy D and Tofler GH; Framingham Heart Study: Genetic and environmental contributions to platelet aggregation: The Framingham heart study. Circulation 103 3051-3056, 2001

41. Lemkes BA, Bähler L, Kamphuisen PW, Stroobants AK, Van Den Dool EJ, Hoekstra JB, Nieuwland R, Gerdes VE and Holleman F: The influence of aspirin dose and glycemic control on platelet inhibition in patients with type 2 diabetes mellitus. J Thromb Haemost 10: 639-646, 2012.

42. Al-Kafaji G and Golbahar J: High glucose-induced oxidative stress increases the copy number of mitochondrial DNA in human mesangial cells. Biomed Res Int 2013: 754946, 2013.

43. Pastukh VM, Gorodnya OM, Gillespie MN and Ruchko MV: Regulation of mitochondrial genome replication by hypoxia: The role of DNA oxidation in D-loop region. Free Radic Biol Med 96: 78-88, 2016.

44. Santos JM, Tewari S and Kowluru RA: A compensatory mechanism protects retinal mitochondria from initial insult in diabetic retinopathy. Free Radic Biol Med 53: 1729-1737, 2012. 